\title{
Editorial from guest editors current Euratom legislation (DE 59/2013): new patient management in radiation protection
}

\author{
Giuseppe Guglielmi ${ }^{1} \cdot$ Antonio Pinto $^{2} \cdot$ Sergio Salerno $^{3}$ (1)
}

Received: 29 May 2019 / Accepted: 6 August 2019 / Published online: 29 August 2019

(c) Italian Society of Medical Radiology 2019

Keywords Euratom legislation $\cdot$ Radiation protection $\cdot$ Radiation dose

It is our great pleasure to introduce this issue of "La Radiologia Medica" focussed in the current Euratom legislation on radiation protection. The new European Directive 2013/59/ Euratom [1] lays down basic safety standards for protection against the risk arising from exposure to ionizing radiation. Furthermore, the new European Directive replacing and integrating in some cases the previous Directives 89/618/ Euratom, 90/641/Euratom, 96/29/Euratom, 97/43/Euratom and 2003/122/Euratom, is expected to have a significant and constructive impact on European radiodiagnostic and radiotherapeutic procedures. One of the main goals of the Directive, born based on the continuous increase of radiation exposure of general population for medical reason, is the information and communication to the patients. New scientific data on tissue reactions call for the optimization principle to be applied to equivalent doses as well, where appropriate, in order to keep doses as low as reasonably achievable, ALARA principle. This new Directive should also follow new International Commission on Radiation protection (ICRP) guidance on the limit for equivalent dose for the lens of the eye in occupational exposure. In the medical area, key technological developments have led to a remarkable increase in the exposure of patients. To this regard, this

Sergio Salerno

sergio.salerno@unipa.it

Giuseppe Guglielmi

giuseppe.guglielmi@unifg.it

Antonio Pinto

antopin1968@libero.it

1 Radiology, Department of Clinical and Experimental Medicine, University of Foggia, Foggia, Italy

2 Department of Radiology, CTO Hospital, Azienda Ospedaliera dei Colli, Naples, Italy

3 Department of Diagnostic Radiology, University of Palermo, Via del Vespro 127, 90127 Palermo, Italy new Directive should underline the need for justification of medical exposure, including the exposure of asymptomatic individuals and should reinforce the requirements concerning information to be provided to patients, the recording and reporting of doses from medical procedures, the use of diagnostic reference levels and the availability of dose-indicating devices. It should be noted also that according to the World Health Organization the concept of health is understood to cover the physical, mental and social well-being of an individual and not merely the absence of disease or infirmity.

In the opening article, Salerno et al. [2] analysed the key factors that influence imaging overuse with X-ray such as self-referral, defensive medicine (diagnostic or therapeutic actions applied mainly to safeguard against potential claims of malpractice rather than to benefit the patient) and duplicate imaging studies. Overuse of medical imaging increases unsustainable costs in the worldwide healthcare systems and exposes both single individuals and general population to unnecessary radiation doses.

Torresin et al. [3] described the wide spectrum of changes introduced by Council Directive 2013/59/Euratom. Relevant changes include new definitions, a new dose limit for the eye lens, non-medical imaging exposures, procedures in asymptomatic individuals, the use and regular review of diagnostic reference levels (including interventional procedures), dosimetric information in imaging systems and its transfer to the examination report, new requirements on responsibilities, the registry and analysis of accidental or unintended exposure and population dose evaluation. Cornacchia et al. [4] highlighted the implications of the new Euratom dose limit for occupational radiation protection in the context of medical occupational radiation exposures. The European Directive 2013/59/Euratom takes into account the new recommendations on reduction in the dose limit for the lens of the eye for planned occupational exposures released in 2012 by ICRP (ICRP document n.118). Factors contributing to 
eye lens dose include: the distance between operator and patient, the incident angle of radiation source, the position of the display unit, which determines the operator's head orientation with regard to the scattered field and the type and position of the protection equipment.

Tomà et al. [5] reviewed the current evidence in radiation protection in paediatric imaging, focusing on the recent knowledge of the biological risk related to low doses exposure. Even if there are no strictly defined limits for patient radiation exposure, it is recommended to try to keep doses low according to ALARA principle. Particularly, article 61 of the European Directive 2013/59/Euratom [1] is focused on children, emphasizing that special attention will be paid to quality assurance programs and to the evaluation of the dose or verification of the activity administered for the practices involving medical exposure of children and to high doses procedures, which may be the case in interventional radiology, nuclear medicine, computed tomography or radiotherapy.

Agostini et al. [6] provided an overview on dose reduction and image quality after the installation of a third-generation dual-source computed tomography in a paediatric radiology department and highlighted the concept that third-generation dual-source computed tomography provides high-quality images with reduced motion artefacts at lower dose.

Agliata et al. [7] compared radiation exposure associated with daily practice cardiovascular examinations performed on two different multidetector computed tomography (MDCT) scanners: a conventional 64-MDCT and a third-generation dual-source (DS) MDCT. In cardiovascular examinations, CT dose index, dose length product, effective dose, exposure time and $\mathrm{Kw}$ were lower and pitch factor was higher with $192 \times 2$-DSCT compared to 64-MDCT.

Salerno et al. [8] analysed the main human factors that may increase patient dose as inaccurate scan over-length and patients positioning in CT colonography (CTC) and their effect in radiation exposure: radiographers and radiologists need to be aware of dose variation and noise effects on vertical positioning and over-scanning. In CTC position, operator's mistake may have higher impact compared to routine abdominal scan due to the double acquisition performed (with patient supine and prone).

Salvatori et al. [9] reviewed patient radiation exposure due to both radiopharmaceutical administration and the CT scan modality and emphasized also the practical ways to reduce the radiation dose to the patients being considered for hybrid imaging procedures such as single-photon emission computed tomography/computed tomography (SPECT/CT) and positron emission tomography/computed tomography (PET/CT).

Magrini et al. [10] described several contemporary and emerging concerns related to radioprotection in radiation therapy, including quality and safety in external beam radiotherapy and brachytherapy, foetal dose, secondary malignancies and the safety issues related to the new techniques and treatment strategies.

In the last closing article, Cornacchia et al. [11] reported the information regarding patient exposure to ionizing radiations in the radiological report, according to the European Directive 2013/59/Euratom (EU 2013/59 art.58(b)): for such purpose, results from other Member States EU 2013/59 transpositions and from guidelines recommendation published by International Organizations involved in diagnostic radiology have been evaluated. This research underlines that there is not a shared interpretation of patient exposure information to be included in radiological report.

As guest editors of this special issue of "La Radiologia medica", we would like to thank all the authors for their excellent contributions and Andrea Giovagnoni, Editor-inChief of the Journal, for giving us the opportunity to coordinate this issue.

\section{Compliance with ethical standards}

Conflict of interest The authors declare they have no conflict of interest.

Ethical approval This article does not contain any studies with human participants performed by any of the authors but is e-review of current clinical cases.

\section{References}

1. EC (2013) Council Directive 2013/59/Euratom of 5 December 2013 laying down basic safety standards for protection against the dangers arising from exposure to ionising radiation, and repealing Directives 89/618/Euratom, 90/641/Euratom, 96/29/Euratom, 97/43/Euratom and 2003/122/Euratom

2. Salerno S, Laghi A, Cantone MC, Sartori P, Pinto A, Frija G (2019) Overdiagnosis and overimaging: an ethical issue for radiological protection. Radiol Med. https://doi.org/10.1007/s1154 7-019-01029-5

3. Torresin A, Evans S, Lizio D, Pierotti L, Stasi M, Salerno S (2019) Practical recommendations for the application of DE 59/2013. Radiol Med. https://doi.org/10.1007/s11547-019-01031

4. Cornacchia S, Errico R, La Tegola L, Maldera A, Simeone G, Fusco V, Niccoli-Asabella A, Rubini G, Guglielmi G (2019) The new lens dose limit: implication for occupational radiation protection. Radiol Med. https://doi.org/10.1007/s11547-019-01027-7

5. Tomà $\mathrm{P}$, Bartoloni $\mathrm{A}$, Salerno $\mathrm{S}$, Granata $\mathrm{C}$, Cannatà V, Magistrelli A, Arthurs OJ (2019) Protecting sensitive patient groups from imaging using ionizing radiation: effects during pregnancy, in fetal life and childhood. Radiol Med. https://doi.org/10.1007/ s11547-019-01034-8

6. Agostini A, Mari A, Lanza C, Schicchi N, Borgheresi A, Maggi S, Giovagnoni A (2019) Trends in radiation dose and image quality for pediatric patients with a multidetector CT and a thirdgeneration dual-source dual-energy CT. Radiol Med. https://doi. org/10.1007/s11547-019-01037-5 
7. Agliata G, Schicchi N, Agostini A, Fogante M, Mari A, Maggi S, Giovagnoni A (2019) Radiation exposure related to cardiovascular CT examination: comparison between conventional 64-MDCT and third-generation dual-source MDCT. Radiol Med. https://doi. org/10.1007/s11547-019-01036-6

8. Salerno S, Lo Re G, Bellini D, Rengo M, Marrale M, Terranova MC, Scopelliti L, Laghi A (2019) Patient centring and scan length:how inaccurate practice impacts on radiation dose in CT colonography (CTC). Radiol Med. https://doi.org/10.1007/s1154 7-019-01021-Z

9. Salvatori M, Rizzo A, Rovera G, Indovina L, Schillaci O (2019) Radiation dose in nuclear medicine: the hybrid imaging. Radiol Med. https://doi.org/10.1007/s11547-019-00989-y

10. Magrini SM, Pasinetti N, Belgioia L, Triggiani L, Levis M, Ricardi U, Corvò R (2019) Applying Radiation Protection and
Safety in Radiotherapy. Radiol Med. https://doi.org/10.1007/ s11547-019-01043-7

11. Cornacchia S, Errico R, Balzano RF, Fusco V, Maldera A, Pierpaoli E, Ferrari C, Rubini G, Guglielmi G (2019) Medical radiological procedures: which information would be chosen for the report? Radiol Med. https://doi.org/10.1007/s1154 7-019-01032

Publisher's Note Springer Nature remains neutral with regard to jurisdictional claims in published maps and institutional affiliations. 